\title{
Clinical analysis of cases of neonatal Streptococcus agalactiae sepsis
}

\author{
S.J. Zeng ${ }^{1,2}$, X.S. Tang ${ }^{3}$, W.L. Zhao ${ }^{1,4}$, H.X. Qiu ${ }^{2}$, H. Wang ${ }^{5}$ and Z.C. Feng ${ }^{1}$ \\ ${ }^{1}$ Department of Neonatology, \\ BaYi Children's Hospital Affiliated to the Clinical Medical College at Beijing \\ Military General Hospital of Southern Medical University, Beijing, China \\ ${ }^{2}$ Department of Neonatology, \\ Longgang District Central Hospital of Shenzhen, Shenzhen, China \\ ${ }^{3}$ Department of Oncology, \\ Longgang District Central Hospital of Shenzhen, Shenzhen, China \\ ${ }^{4}$ Department of Pediatrics, \\ Chengdu Military Common Hospital, Chengdu, China \\ ${ }^{5}$ Microbiological Laboratory, \\ Longgang District Central Hospital of Shenzhen, Shenzhen, China \\ Corresponding author: Z.C. Feng \\ E-mail: zhichunfeng2015@sina.com
}

Genet. Mol. Res. 15 (2): gmr.15027962

Received October 29, 2015

Accepted February 19, 2016

Published June 17, 2016

DOI http://dx.doi.org/10.4238/gmr.15027962

\begin{abstract}
With the advent of antibiotic resistance, pathogenic bacteria have become a major threat in cases of neonatal sepsis; however, guidelines for treatment have not yet been standardized. In this study, 15 cases of neonatal Streptococcus agalactiae sepsis from our hospital were retrospectively analyzed. Of these, nine cases showed early-onset and six cases showed late-onset sepsis. Pathogens were characterized by genotyping and antibiotic sensitivity tests on blood cultures. Results demonstrated that in cases with early-onset sepsis, clinical manifestations affected mainly the respiratory tract, while lateonset sepsis was accompanied by intracranial infection. Therefore, we suggest including a cerebrospinal fluid examination when diagnosing
\end{abstract}


neonatal sepsis. Bacterial genotyping indicated the bacteria were mainly type Ib, Ia, and III S. agalactiae. We recommend treatment with penicillin or ampicillin, since bacteria were resistant to clindamycin and tetracycline. In conclusion, our results provide valuable information for the clinical treatment of $S$. agalactiae sepsis in neonatal infants.

Key words: Streptococcus agalactiae; Sepsis; Infant; Newborn; Drug resistance

\section{INTRODUCTION}

The composition of pathogenic bacteria causing neonatal sepsis varies with age and geography. During the 1930s and 1940s, group A $\beta$-hemolytic Streptococcus was the main pathogenic bacterium, while from the 1950s to the 1960s Escherichia coli became the dominant species. Since the 1970s, group B Streptococcus (GBS) has become the most common pathogenic bacterium in the United States. In China, Staphylococcus was the most common pathogenic bacterium for many years, followed by Escherichia coli, while Streptococcus remains rare. Data on Streptococcus agalactiae infection in newborns are currently very limited. In this study, we characterized the clinical features, genotype, and drug resistance of neonatal $S$. agalactiae sepsis in our hospital in recent years. This may provide valuable guidance for clinical diagnosis and treatment.

\section{MATERIAL AND METHODS}

\section{Ethics statement}

Institutional Ethics Board approval was obtained from the Medical Ethics Committee of Shenzhen Longgang Central Hospital. All legal guardians of participating subjects were formally informed of the purpose of this study, and their written informed consent was obtained.

\section{Data sources}

A total of 15 patients confirmed with neonatal $S$. agalactiae sepsis admitted to Shenzhen Longgang Central Hospital between January 2012 and December 2014 were enrolled in this study.

\section{Methods}

\section{Retrospective analysis}

A retrospective analysis was conducted for all clinical data obtained, such as: hospitalization age, onset age, gender, gestational age, delivery, neonatal condition, birth weight, clinical manifestations, human C-reactive protein (hCRP) test, biochemical tests, imaging, cerebrospinal fluid tests, blood culture, antibiotic sensitivity tests, and auxiliary examination results. Application of antibiotics, clinical outcome, and prognosis were also recorded. 


\section{Bacterial genotyping method}

The isolated bacterial strains were cultured and identified using a VITEK-AMS automatic microbial analyzer (BioMérieux, Chicago, IL, USA). DNA was extracted using a bacterial DNA extraction kit (Foregene, Chengdu, China), and a DNA fragment was amplified by PCR using a primer set synthesized by Shanghai Sangong (Shanghai, China). Primer design, gene sequencing, and genotyping were conducted as previously described (Kong et al., 2002, 2005).

\section{Diagnostic criteria}

The diagnostic criteria followed the Diagnosis and Treatment Program of Neonatal Sepsis issued by the National Neonatal Conference in 2003. Briefly, diagnostic criteria included: 1) presence of pathogenic bacteria in the blood or sterile body cavity; 2) presence of a conditional pathogen in blood specimens, suggesting the same pathogen may reside in blood, sterile body cavity, or ducts.

\section{Statistical methods}

Statistical analysis was conducted using SPSS 19.0 software. Data are reported as means \pm standard deviation. Univariate comparison of means was evaluated using the Student $t$-test; $\mathrm{P}<0.05$ was considered as statistically significant.

\section{RESULTS}

\section{General overview}

Of all 53 cases of sepsis, the proportion of S. agalactiae sepsis was 15/53 (28.3\%), down from 11/25 (44\%) in 2012. Between 2012 and 2014, 17,905 neonates were admitted to our hospital and the infection rate was estimated to be $0.8 / 1000$ (95\%CI $0.5-1.3)$. Of the 15 patients with neonatal S. agalactiae sepsis, seven (46.7\%) were male and eight $(53.3 \%)$ were female patients, whereas two $(13.3 \%)$ cases were premature and $13(86.7 \%)$ were full term infants. Three (20\%) neonates weighed between 1500 and $2499 \mathrm{~g}$, and $12(80 \%)$ weighed between 2500 and $4000 \mathrm{~g}$. Nine (60\%) neonates were aged less than 7 days, and six (40\%) were older than 7 days. Eleven (73.3\%) births were vaginal, and four $(26.7 \%)$ involved caesarean section. All neonates were hospitalized within 2 days of becoming sick.

\section{Clinical manifestation}

Six cases presented with fever, eight showed dyspnea, and four displayed a poor response. In addition, there were five cases of hyperbilirubinemia; four of pneumonia, including three $(75 \%)$ with early infection; and five of purulent meningitis, of which four $(80 \%)$ were late infections.

\section{Laboratory examination}

White blood cell (WBC) counts revealed three cases with $\mathrm{WBC}<4 \times 10^{9} / \mathrm{L}$, eight with 
WBC $>4 \times 10^{9} / \mathrm{L}$ and $<20 \times 10^{9} / \mathrm{L}$, and four with $\mathrm{WBC}>20 \times 10^{9} / \mathrm{L}$. There was one case with $\mathrm{hCRP}<15 \mathrm{mg} / \mathrm{L}$, three with hCRP $>15 \mathrm{mg} / \mathrm{L}$ and $<50 \mathrm{mg} / \mathrm{L}$, seven cases with hCRP $>50 \mathrm{mg} / \mathrm{L}$ and $<100 \mathrm{mg} / \mathrm{L}$, and four with $\mathrm{hCRP}>100 \mathrm{mg} / \mathrm{L}$.

\section{Antibiotic sensitivity tests}

A total of 30 strains of S. agalactiae were identified. Antibiotic sensitivity tests showed that all strains were sensitive to penicillin, ampicillin, tigecycline, erythromycin, vancomycin, and linezolid (100\% rate). However, sensitivity rates to ciprofloxacin, moxifloxacin and levofloxacin, clindamycin, and tetracycline were $88.9,86.7,13.3$, and $6.7 \%$, respectively (Table 1).

\section{Table 1. Drug sensitivity of 30 strains of Streptococcus agalactiae.}

\begin{tabular}{l|c|c}
\hline Drugs & Drug sensitivity & Drug resistance \\
\hline Penicillin & $30 / 30(100)$ & $0 / 30(0)$ \\
\hline Ampicillin & $30 / 30(100)$ & $0 / 30(0)$ \\
\hline Clindamycin & $4 / 30(13.3)$ & $26 / 30(86.7)$ \\
\hline Tetracycline & $2 / 30(6.7)$ & $0 / 30(0)$ \\
\hline Tigecycline & $30 / 30(100)$ & $4 / 30(13.3)$ \\
\hline Ciprofloxacin & $26 / 30(86.7)$ & $4 / 30(13.3)$ \\
\hline Levofloxacin & $26 / 30(86.7)$ & $2 / 18(11.1)$ \\
\hline Moxifloxacin & $16 / 18(88.9)$ & $0 / 30(0)$ \\
\hline Furantoin & $30 / 30(100)$ & $0 / 30(0)$ \\
\hline Vancomycin & $30 / 30(100)$ & $0 / 30(0)$ \\
\hline Linezolid & $30 / 30(100)$ & \\
\hline
\end{tabular}

Values are reported as cases/total (\%).

\section{Pathogen genotyping}

Genotyping results showed that three cases $(20 \%)$ were $S$. agalactiae type Ia, four (26.7\%) were type Ib, and eight (53.3\%) were type III.

\section{Treatment and prognosis}

Before the identity of the pathogen was confirmed, all 15 cases were treated with broad-spectrum antibiotics such as penicillin. Application of penicillin was continued after antibiotic sensitivity tests since all strains were sensitive to penicillin and ampicillin. However, three cases were treated with vancomycin due to a poor response with penicillin. The course of treatment was three or two weeks for patients with or without intracranial infection, respectively. Finally, 12 cases were cured and three showed improvement and were discharged with insufficient course of treatment due to their personal reasons. No case of death was reported.

\section{DISCUSSION}

The high prevalence of bacterial infection in neonates is a major cause of neonatal death. In recent decades, considerable attention has been paid to neonatal bacterial infections caused by group B Streptococcus (GBS) in Western countries, and anti-microbial strategies 
have changed over time (Verani et al., 2010; Baker et al., 2011; Alós Cortés et al., 2012). Maternal GBS screening, common in Western countries, is not applied in China, resulting in a higher incidence of $S$. agalactiae infections, particularly among newborns (Xiaoyi and Zhiwei, 2012), and serious cases were occasionally reported.

In this study, 15/53 (28.3\%) cases diagnosed with neonatal septicemia showed $S$. agalactiae sepsis.

GBS, also known as $S$. agalactiae, is a gram-positive bacterium, generally located in the stomach and urinary tract of healthy individuals. However, in infants younger than 3 months, GBS can cause pneumonia, sepsis, and meningitis. GBS infection is defined as earlyonset disease if it occurs at age 0-6 days, or late-onset if it occurs at age 7-89 days. In this study, nine cases were early-onset sepsis and six were late-onset sepsis, consistent with a previous report (Weihong et al., 2014). Early-onset is caused by maternal-neonatal transmission at the time of delivery and presents as septicemia, pneumonia, and meningitis. Late-onset GBS sepsis is not associated with delivery, and presents mainly as fever or combined meningitis (Sparks et al., 2007). Late-onset GBS sepsis is observed mainly in premature infants (Berardi et al., 2013), and is associated with fewer anti-GBS antibodies in the neonatal body. Active transport of GBS antibodies occurs for 34 weeks during pregnancy, but decreases steadily after delivery. The pathogenesis of GBS-derived meningitis is not fully understood, but it is characterized by acute onset and rapid progression with complications observed in $62 \%$ of patients after hospitalization. Convulsion, drowsiness, coma, and respiratory distress have been observed, with mechanical ventilation support required in some cases. The prognosis is always poor if WBC count is $<5 \times 10^{9} / \mathrm{L}$, initial cerebrospinal fluid protein is $\geq 300 \mathrm{mg} / \mathrm{dL}$, or blood sugar is $<1.1 \mathrm{mM}$. If the hearing ability test is not cleared, abnormal signs of the nervous system, such as twitching, may indicate a substantial risk of death or disability at a later stage (Libster et al., 2012).

Previous studies suggested that the isolated bacterial strains were highly sensitive to penicillin and vancomycin, but resistance to erythromycin and clindamycin was on the rise, which was consistent with our observation (Shore and Yudin, 2012; Weihong et al., 2014). According to the United States Center for Disease Control (CDC), penicillin and ampicillin should be used as the first line of treatment for GBS infection and prevention (Verani et al., 2010). In this study, penicillin and ampicillin were prescribed to all patients, except three who were treated with vancomycin, in line with the CDC's proposal.

Bacterial genotyping identified three cases of S. agalactiae type Ia (20\%), four of type Ib (26.7\%), and eight of type III (53.3\%). In accordance with a previous study (Matsubara et al., 2013), our results show that genotype distribution differs by country and region. For example, Ia, II, III, and V are the main serotypes in Europe and the United States (Skoff et al., 2009; Tazi et al., 2011), while Ia and IV are dominant in Malaysia (Karunakaran et al., 2009).

Finally, according to our results, the incidence of GBS among patients admitted to our hospital is $0.8 / 1000$ (95\%CI 0.5-1.3). Patients with GBS-derived pneumonia were included, since GBS pneumonia was previously reported to be higher in developing countries (Matsubara et al., 2013). Considering the small sample size, further investigation is required to confirm our results. Moreover, our data support the benefits of GBS screening during pregnancy for neonatal GBS prevention in China. Currently, pregnancy GBS screening includes bacterial culture of a rectal or vaginal swab, PCR, Xpert GBS PCR, ChromID Strepto B, SStrep B OIA rapid detection, and other methods. Intrapartum antibiotic prophylaxis would reduce the 
incidence of early-onset GBS infection by $65 \%$, while also reducing the severity of late-onset disease (Ko et al., 2010). A GBS vaccine is likely to be the most effective preventive strategy, both in pregnant women and newborns (Kim et al., 2014). A GBS polysaccharide-protein conjugate vaccine has completed phase two of a trial in South Africa, and has been shown to prevent both early- and late-onset infection.

\section{Conflicts of interest}

The authors declare no conflict of interest.

\section{ACKNOWLEDGMENTS}

Research supported by grants from the China Postdoctoral Science Foundation (Grant \#2013M532139), and the Science and Technology Bureau financing project of Longgang District, Shenzhen (Grant \#201406063001034).

\section{REFERENCES}

Alós Cortés JI, Andreu Domingo A, Arribas Mir L, Cabero Roura L, et al. (2012). [Prevention of perinatal group B Streptococcal disease. Updated Spanish recommendations 2012]. Rev. Esp. Quimioter. 25: 79-88.

Baker CJ, Byington CL and Polin RA; Committee on Infectious Diseases; Committee on Fetus and Newborn (2011). Policy statement - Recommendations for the prevention of perinatal group B streptococcal (GBS) disease. Pediatrics 128: 611-616.

Berardi A, Rossi C, Lugli L, Creti R, et al.; GBS Prevention Working Group, Emilia-Romagna (2013). Group B streptococcus late-onset disease: 2003-2010. Pediatrics 131: e361-e368. http://dx.doi.org/10.1542/peds.2012-1231

Karunakaran R, Raja NS, Hafeez A and Puthucheary SD (2009). Group B Streptococcus infection: epidemiology, serotypes, and antimicrobial susceptibility of selected isolates in the population beyond infancy (excluding females with genital tract- and pregnancy-related isolates) at the University Malaya Medical Centre, Kuala Lumpur. Jpn. J. Infect. Dis. 62: 192-194.

Kim SY, Russell LB, Park J, Verani JR, et al. (2014). Cost-effectiveness of a potential group B streptococcal vaccine program for pregnant women in South Africa. Vaccine 32: 1954-1963. http://dx.doi.org/10.1016/j.vaccine.2014.01.062

Ko TJ, Hsieh WS, Hsueh PR, Chou HC, et al. (2010). Late-onset group B streptococcal meningitis in a neonate with early antibiotic prophylaxis. Pediatr. Neonatol. 51: 242-244. http://dx.doi.org/10.1016/S1875-9572(10)60046-0

Kong F, Gowan S, Martin D, James G, et al. (2002). Serotype identification of group B streptococci by PCR and sequencing. J. Clin. Microbiol. 40: 216-226. http://dx.doi.org/10.1128/JCM.40.1.216-226.2002

Kong F, Ma L and Gilbert GL (2005). Simultaneous detection and serotype identification of Streptococcus agalactiae using multiplex PCR and reverse line blot hybridization. J. Med. Microbiol. 54: 1133-1138. http://dx.doi.org/10.1099/ jmm.0.46244-0

Libster R, Edwards KM, Levent F, Edwards MS, et al. (2012). Long-term outcomes of group B streptococcal meningitis. Pediatrics 130: e8-e15. http://dx.doi.org/10.1542/peds.2011-3453

Matsubara K, Hoshina K and Suzuki Y (2013). Early-onset and late-onset group B streptococcal disease in Japan: a nationwide surveillance study, 2004-2010. Int. J. Infect. Dis. 17: e379-e384. http://dx.doi.org/10.1016/j. iiid.2012.11.027

Shore EM and Yudin MH (2012). Choice of antibiotic for group B streptococcus in women in labour based on antibiotic sensitivity testing. J. Obstet. Gynaecol. Can. 34: 230-235. http://dx.doi.org/10.1016/S1701-2163(16)35183-0

Skoff TH, Farley MM, Petit S, Craig AS, et al. (2009). Increasing burden of invasive group B streptococcal disease in nonpregnant adults, 1990-2007. Clin. Infect. Dis. 49: 85-92. http://dx.doi.org/10.1086/599369

Sparks JR, Recchia FM and Weitkamp JH (2007). Endogenous group B streptococcal endophthalmitis in a preterm infant. J. Perinatol. 27: 392-394. http://dx.doi.org/10.1038/sj.jp.7211685

Tazi A, Morand PC, Réglier-Poupet H, Dmytruk N, et al. (2011). Invasive group B streptococcal infections in adults, France (2007-2010). Clin. Microbiol. Infect. 17: 1587-1589. http://dx.doi.org/10.1111/j.1469-0691.2011.03628.x 
Verani JR, McGee L and Schrag SJ; Division of Bacterial Diseases, National Center for Immunization and Respiratory Diseases, Centers for Disease Control and Prevention (CDC) (2010). Prevention of perinatal group B streptococcal disease - revised guidelines from CDC, 2010. MMWR Recomm. Rep. 59 (RR-10): 1-36.

Weihong F, Mancang Z and Jie L (2014). Analysis of drug resistance of streptococcus agalactiaemoniae in 42 cases. Int. J. Med. Lab. Med. 17: 2309-2310.

Xiaoyi H and Zhiwei (2012). Analysis of early onset blood flow in the neonatal maternal and child health hospital. Chin. J. Infect. Med. 11: 2329-2332. 